\title{
For Gender Equality in Science
}

\author{
"Why is science useless to us? \\ Because we are excluded from public office; \\ And why are we excluded from public office? \\ Because we have no science." \\ (Nísia Floresta, Women's Rights, and Men's Injustice, 1832) ${ }^{1}$
}

Science concerns facts and observations, analysis and models, constant rationalization. Scientists routinely deal with the unknown, 'brainstorms', rediscoveries, invention. In the fantastic history of human art and knowledge, it is fascinating to see brilliant minds captured by intellectual challenges and, from them, attempting to glimpse the limits of the universe, biology, time, life and existence itself.

Transforming our world and promoting inclusion is a current intellectual, social, scientific, and political challenge. Sadly, it seems not to be fully understood as such, not even by some scientists, let alone the population as a whole. Some people lack sensibility, empathy, education or culture - or probably a combination of them - as it seems hard for them to see why other people have the (fundamental) right to be included. It takes a lot of effort to look around and realize that not all players start the game of life on an equal basis, or receive comparable support from family or government, to achieve decent final scores after each match. It is usually much simpler to disguise prejudice or lack of understanding behind "merit-only" based claims, and by extension despise empowering policies, arguing that resources are limited or blaming the victims, when in fact inclusion requires effort, intelligence and, above all, willingness. Human beings can be, in truth, astonishingly selfish, or ignorant.

It is a fact that about fifty percent of the world's human population is female, carrying an undeniable potential to participate in social and economic development. It is also a fact that physical violence, femicide, sexual harassment, child marriage, teenage maternity, and legal barriers to entering school are still a terrifying part of the daily routine of at least a third of the women in developing countries worldwide. ${ }^{2}$ Some of these conditions strongly correlate with lower incomes and low levels of education. Brazil has unfortunately been included in some shameful statistical reports in this sense, ${ }^{3}$ and news of rising violence against women and minorities in 2019 signal a very embarrassing setback in a country currently plunged into deep political polarization added to persistent economic and social inequalities.

Even in those countries where they have gained sufficient respect to be admitted to public debate and integrate the workforce, women frequently occupy supporting positions or no rare are underpaid when compared to men who perform the same activities. It is in this context that motherhood, a concept inherent and fundamental to most women's life may become deeply conflicting, a source of guilt and psychological unbalance, besides being an evil motive for hidden, or even open, workplace discrimination. Efficiency expectations placed upon women no rare oppose maternity and career to a point in which, for lack of essential childcare support, flexible working hours or sharing of domestic responsibilities, they leave their jobs or decide to work part-time at the expense of their professional fulfillment, while their partners rarely face a similar personal struggle.

It is also true that, mainly as a consequence of historic discrimination ${ }^{4}$ and late access to education and opportunities, women are significantly underrepresented in almost every high-profile human activity, including political leadership, business management and, unfortunately, science. ${ }^{5}$ In this sense, Nísia Floresta's claim reproduced at the beginning of this text, she who was a groundbreaker Brazilian writer and educator far ahead of her time, is still strikingly current. As an example, among the 908 individuals who have been awarded the Nobel Prize between 1901 and 2018, the distinction has honored 51 women, with Marie Curie awarded twice. ${ }^{6}$ This number represents only $5.6 \%$ of the total laureates, a very unsettling score. Especially in Chemistry, just five female researchers have ever been distinguished with the prize, namely Marie Curie (1911), Irène Joliot-Curie (1935), Dorothy Crowfoot Hodgkin (1964), Ada E. Yonath (2009) and Frances H. Arnold (2018). Fortunately, the recent 2001-2018 period has seen a rise of $100 \%$ in the number of female laureates as compared to the previous twenty years, and this will hopefully become a tendency.

Promoting the inclusion of women and girls implies to create opportunities for intellectual growth and to fight inequalities in access to skills, health, education, protection, profession, and well-being. In this context, it is stimulating to follow the promising worldwide progress towards the implementation of the 2030 United Nations' Agenda for Sustainable Development, which includes the achievement of gender equality and empowerment of all women and girls as a goal. ${ }^{2}$ The commitment of world leaders to this Agenda has given rise to several cheering initiatives, although there is still a long way to go before we genuinely approach sustainable development through the necessary combination of economic growth, social inclusion, and environmental protection.

Among these healthy initiatives, inspiring Brazilian chemists such as Aïda Spinola, Aída Hassón-Voloch, Anita Dolly Panek, Blanka Wladislaw, Eloisa Biosotto Mano, Glaci Teresinha Zancan, Lucia Piave Tosi, Maria Auxiliadora Coelho Kaplan, Ottilia Rodrigues Affonso Mitidieri and Yvonne Primerano Mascarenhas had their life and careers distinguished by CNPq through the project called "Pioneiras da Ciência" (Women Pioneers in Science). ${ }^{7}$ Started in 2013 and currently in its $7^{\text {th }}$ edition, this project aims to highlight the history of women researchers who contributed to the development and formation of human resources for science and technology in Brazil. To this recognition we add the names of Helena Bonciani Nader and Vanderlan da Silva Bolzani for, together with Glaci Zancan, building chemical knowledge and fighting for national science and education as past presidents of the Brazilian Chemical Society (SBQ) and the Brazilian Society for the Advancement of Science (SBPC). May their contributions motivate many young minds, both male and female, and institutions, towards creating equal and real educational opportunities for all.

To add to these efforts and mark the $30^{\text {th }}$ anniversary of its first launching in 1990, the Journal of the Brazilian Chemical Society now publishes a special volume to honor the work of distinguished Brazilian Women in Chemistry. It contains original contributions in all aspects of Chemistry within the scope of the JBCS, submitted by women research leaders who illustrate and represent the quality of the current Brazilian chemical science. Given the enthusiastic welcome given by the community to this idea, reflected in the high number of submissions received for this special volume, the original proposal to release it in just one issue has been expanded to three. As part of this successful initiative of the Brazilian Chemical Society, the Editorial Board of the JBCS thanks all authors for considering our invitation and joining us on this special anniversary celebration.

"All spiritual perfection is a real benefit: Well then, science is spiritual perfection: So science is a real benefit." (Princess Isabel file, Grão Pará Archive) ${ }^{4}$

Maria D. Vargas ${ }^{(1)}$ Special Issue Guest Editor Universidade Federal Fluminense (UFF), Niterói-RJ, Brazil

Jaísa F. Soares ${ }^{(1)}$

Editor of the JBCS

Universidade Federal do Paraná(UFPR), Curitiba-PR, Brazil

\section{References}

1. Padilha, E. L. (Coordenação); Bezerra, G. B. A. (Organização); Duarte, C. L.; Pessoa, U. (Colaboração); Nísia Floresta Brasileira Augusta: uma Mulher à frente do seu Tempo; Fundação Ulysses Guimarães: Brasília, 2017.

2. https://www.un.org/sustainabledevelopment/development-agenda/ accessed in September 2019.

3. https://oig.cepal.org/en/indicators/femicide-or-feminicide accessed in September 2019.

4. Filgueiras, C. A. L.; Quim. Nova 2004, 27, 349.

5. Bolzani, V. S.; Cienc. Cult. 2017, 69, 56.

6. https://www.nobelprize.org/prizes/lists/nobel-prize-awarded-women/ accessed in September 2019.

7. http://www.cnpq.br/web/guest/pioneiras-da-ciencia1 accessed in September 2019. 